\title{
PENGARUH LITERASI DIGITAL DAN EFEKTIVITAS APLIKASI SIKAD TERHADAP KUALITAS PELAYANAN DAN KEPUASAAN MAHASISWA FAKULTAS ILMU PENDIDIKAN UNIVERSITAS MUHAMMADIYAH JAKARTA
}

\author{
Suci Mulya Lestari, Iswan, Ahmad Suryadi \\ Fakultas Ilmu Pendidikan, Universitas Muhammadiyah Jakarta \\ Email: uci_cinta@yahoo.com; iswan@umj.ac.id; ahmad.suryadi@umj.ac.id.
}

\begin{abstract}
This study aims to determine the effect of digital literacy and the effectiveness of the application of Sikad which is an online academic application on the quality of service and satisfaction of students as users. The study was conducted at the Faculty of Education at the University of Muhammadiyah Jakarta with respondents selected by random sampling of 90 students consisting of 5 study programs, namely: $P G-$ PAUD, PGSD, Mathematics, PBSI, and PBI. This research uses a quantitative approach with survey methods and data analysis techniques using path analysis. The results of this study indicate that of the 7 research results, 3 of them are positive and significant, namely: The effect of the effectiveness of the application of the attitude on the quality of service is significant ( $T$ hitung $>$ T table $=2.776>1.98$ and $P$ value $<0.05=0.006<0.05)$; The effect of service quality on user satisfaction is significant $(69,969>1.98$ and $0,000<0.05)$; The effect of digital literacy on user satisfaction through significant service quality $(2,803>1.98$ and $0.005<0.05)$.
\end{abstract}

Keywords: digital literacy, effectiveness, Sikad, application, service quality, user satisfaction

\section{ABSTRAK}

Penelitian ini bertujuan untuk mengetahui pengaruh literasi digital dan efektivitas aplikasi Sikad yang merupakan aplikasi akademik online terhadap kualitas pelayan dan kepuasaan mahasiswa sebagai pengguna. Penelitian dilakukan di Fakultas Ilmu Pendidikan Universitas Muhammadiyah Jakarta dengan responden yang dipilih secara random sampeling sebanyak 90 mahasiswa yang terdiri dari 5 program studi, yaitu: PG-PAUD, PGSD, Pendidikan Matematika, PBSI, dan PBI. Penelitian ini menggunakan pendekatan kuantitatif dengan metode survey dan teknik analisis data menggunakan analisis jalur (path analysis). Hasil penelitian ini menunjukan bahwa dari 7 hasil penelitian, 3 di antaranya bernilai postif dan signifikan, yaitu: Pengaruh efektivitas aplikasi Sikad terhadap kualitas pelayanan signifikan (Thitung $>$ Ttabel $=2.776>1.98$ dan Pvalue $<0.05=0.006<0.05$ ); Pengaruh kualitas pelayanan terhadap kepuasan pengguna signifikan (69.969>1.98 dan 0.000<0.05); Pengaruh literasi digital terhadap kepuasan pengguna melalui kualitas pelayanan signifikan $(2.803>1.98$ dan $0.005<0.05)$.

Kata kunci: literasi digital, efektivitas, aplikasi Sikad, kualitas pelayanan, kepuasan pengguna

\section{PENDAHULUAN}

Kemajuan teknologi saat ini sangat berkembang pesat, ditandai dengan berbagai aktifitas yang sudah dilakukan menggunakan berbagai perangkat teknologi. Dengan kehadiran teknologi yang semakin berkembang, hal tersebut dapat dilakukan dengan sangat mudah. Begitu juga dengan kehadiran teknologi pada dunia pelayanan pendidikan.

Pelayanan informasi akademik berbasis online diharapkan dapat membantu memangkas waktu yang relatif singkat demi menunjang kebutuhan akademik bagi mahasiswa dan dosen. Berangkat dari sinilah, di tahun kedua Fakultas Ilmu Pendidikan (FIP) baru menggunakan 
layanan informasi akademik berbasis online yang diberi nama Sistem Informasi Akademik (Sikad). Sikad merupakan program akademik berbasis online yang dapat diakses oleh semua civitas akademika di lingkungan Fakultas Ilmu Pendidikan. Sikad dapat membantu hampir semua pelayanan ke akademikaan di FIP. Mahasiswa dan dosen mengetahui informasi dan dapat melakukan pelayanan akademik melalui program Sikad, dengan beberapa ketentuan yang telah ditetapkan Fakultas.

Literasi digital menjadi kebutuhan mendesak bagi masyarakat saat ini, terutama bagi para kaum intelektual seperti mahasiswa. Sebab kemajuan teknologi yang diimbangi oleh kecerdasan dalam menggunakan perangkat teknologi modern, akan memberikan dampak kemudahan bagi kehidupan, begitu juga sebaliknya. Literasi digital juga menjadi bagian dari rencana jangka panjang Persatuan Bangsa Bangsa yang mengurusi pendidikan dan kebudayaan. Dalam roadmap UNESCO (20152020), literasi digital menjadi bagian terpenting untuk masa depan pendidikan dan menjadi basis pengetahuan, yang didukung oleh teknologi informasi secara terintegrasi.

Berdasarkan latar belakang di atas, maka dalam penelitian ini akan dikaji lebih jauh berkaitan dengan "Pengaruh Literasi Digital dan Efektivitas Aplikasi Sikad Terhadap Kualitas Pelayanan dan Kepuasan Mahasiswa FIP-UMJ".

\section{KAJIAN LITERATUR}

\section{Pengertian Literasi Digital}

Menurut Paul Gilster (dalam Kemendikbud, 2017: 7), literasi digital diartikan sebagai kemampuan untuk memahami dan menggunakan informasi dalam berbagai bentuk baik itu audio ataupun visual dari berbagai sumber yang sangat luas yang diakses melalui perangkat komputer atau digitalisasi. Jadi apapun bentuk dari informasi yang kita terima melalui komputer atau digital disebut dengan Literasi Digital.

Menurut UNESCO konsep literasi digital menjadi landasan penting bagi kemampuan memahami perangkat-perangkat teknologi, informasi dan komunikasi. Misalnya, dalam Literasi TIK (ICT Literacy) yang merujuk pada kemampuan teknis atau penggunaan dan pemakaian yang memungkinkan keterlibatan aktif dari masyarakat, dalam hal ini adalah mahasiswa sebagai civitas akademika sejalan dengan perkembangan teknologi serta pelayanan akademik berbasis digital.

\section{Pengertian Sistem Informasi (Aplikasi SIKAD)}

Menurut Susanto (2013:52) sistem informasi merupakan kumpulan dari sub sistem baik fisik maupun non fisik, hardware ataupun software, yang saling berhubungan satu sama dan bekerja sama secara bersamaan dan sistematis untuk mencapai satu tujuan yaitu mengolah data menjadi informasi yang berguna.

Berdasarkan pengertian sistem informasi di atas, dapat dipahami bahwa sistem informasi merupakan kombinasi dari teknologi informasi dan orang yang menggunakan teknologi itu dalam melakukan aktivitasnya untuk mendukung operasional suatu organisasi dan membantu manajemen dalam mengambil keputusan. Dengan menggunakan sistem informasi kegiatan akan berjalan efektif dan efisien.

Aplikasi Sikad FIP-UMJ merupakan sistem informasi berbasis online yang digunakan FIP-UMJ dalam melalukan kegiatan keakademikaan. User utama pengguna aplikasi ini selain dosen adalah mahasiswa. Aplikasi ini berisikan seluruh kegiatan pelayanan akademik kemahasisswaan dari mulai pengisian biodata, KRS online, nilai dan data kelulusan mahasiswa yang diakses secara online melalui perangkat komputer.

\section{Pengertian Kualitas Pelayanan}

Goetsh dan Davis dikutip Tjiptono (2015:51), mengemukakan bahwa kualitas merupakan suatu kondisi dinamis yang berhubungan dengan produk, jasa, manusia, proses, dan lingkungan yang memenuhi atau melebihi harapan. Dalam artian yang lain adalah 
suatu kondisi apapun yang sesuai dengan harapan atau lebih dari yang kita harapkan.

Definisi sebuah Kualitas Pelayanan merupakan segala sesuatu yang menekankan pada kelebihan dari tingkat kepentingan konsumen sebagai inti dari sebuah pelayanan. Seperti kualitas pelayanan akademik yang ada di FIP-UMJ yang selalu berusaha menekankan pada kepentingan mahasiswa sebagai user utamanya.

\section{Pengertian Kepuasan Pengguna}

Secara umum kepuasan (satisfaction) adalah perasaan senang atau kecewa seseorang yang timbul karena membandingkan kinerja yang dipersepsikan produk (atau hasil) terhadap ekspektasi mereka (Kotler, 2009). Kepuasan di sini dimaksudkan perasaan senang karna hasil dari sesuatu yang sesuai harapan atau bahkan lebih baik dari yang di harapkan.

Rentang waktu kepuasan memang agak sulit tergambarkan. Bisa saja kepuasaan hanya berlaku pada saat sekarang, dan nilai nya akan berubah di waktu yang lain. Kepuasan Pengguna layanan di sini adalah ukuran dari mahasiswa yang menggunakan pelayanan online Sikad dalam pemenuhan kebutuhan akademik.

\section{METODE PENELITIAN}

Penelitian ini dilakukan di Fakultas Ilmu Pendidikan Universitas Muhammadiyah Jakarta antara rentang waktu Desember 2018 sampai dengan April 2019. Responden dipilih secara random sampling sebanyak 90 mahasiswa yang terdiri dari 5 program studi, yaitu: PG-PAUD, PGSD, Pend. Matematika, PBSI, dan PBI angkatan 2015 dan 2016. Penelitian ini menggunakan pendekatan kuantitatif dengan metode survey dan teknik analisis data menggunakan analisis jalur (path analysis).

\section{HASIL DAN PEMBAHASAN}

Penelitian dengan metode Kuantitatif menggunakan Analisis Jalur dan perhitungan statistiknya dengan menggunakan program PLS 3.0 didapatkan hasil sebagai berikut:
Perhitungan uji hipotesis berdasarkan sampel dan tabel $\mathrm{t}$, maka didapatkan standarisasi nilai $\mathrm{t}$ tabel dengan sampel sebanyak 90 responden sebesar 1.98 dengan jenis two tail test $(\alpha=0.05)$.

Perhitungan untuk tingkat pengaruh yang signifikan ditandai dengan $\mathrm{T}$ statistik $>\mathrm{T}$ tabel (1.98) dan $\mathrm{P}$ value $<\alpha(0.05)$. Sedangkan untuk pengaruh yang tidak signifikan ditandai dengan $\mathrm{T}$ statistik $<\mathrm{T}$ tabel (1.98) dan $\mathrm{P}$ value $>\alpha(0.05)$. Namun, apabila yang tidak signifikan tetap mendapat hasil positif (tidak negatif), penelitian ini diterima.

\section{Hasil penelitian ini menunjukkan bahwa:}

1) Pengaruh literasi digital terhadap kualitas pelayanan positif namun tidak signifikan ( $\mathrm{T}$ hitung $<\mathrm{T}$ tabel $=0.964<1.98$ dan $\mathrm{P}$ value $>0.5=0.336>0.05$ );

2) Pengaruh literasi digital terhadap kepuasan pengguna positif namun tidak signifikan ( $T$ hitung $<\mathrm{T}$ tabel $=1.413<1.98$ dan $\mathrm{P}$ value $>0.5=0.158>0.05$ );

3) Pengaruh efektivitas aplikasi Sikad terhadap kualitas pelayanan signifikan (T hitung $>\mathrm{T}$ tabel $=2.776>1.98$ dan $\mathrm{P}$ value $<0.05=0.006<0.05)$;

4) Pengaruh efektivitas terhadap kepuasan pengguna positif namun tidak signifikan $(0.027<1.98$ dan $0.978>0.05)$;

5) Pengaruh kualitas pelayanan terhadap kepuasan pengguna signifikan (69.969> 1.98 dan $0.000<0.05$ );

6) Pengaruh literasi digital terhadap kepuasan pengguna melalui kualitas pelayanan signifikan $(2.803>1.98$ dan $0.005<0.05)$; dan

7) Pengaruh efektivitas aplikasi Sikad terhadap kepuasan pengguna melalui kualitas pelayanan positif namun tidak signifikan $(0.964<1.98$ dan $0.335>0.05)$.

\section{KESIMPULAN}

Dari hasil penelitian diatas dapat ditarik kesimpulan bahwa dari 7 penelitian yang dikaji, di dapat 3 penelitian yang bersifat positif dan signifikan dimana yang satu sangat mempengaruhi yang lain. Itu bisa dilihat pada: 
1) Pengaruh efektivitas aplikasi Sikad terhadap kualitas pelayanan bersifat positif dan sangat signifikan, dimana hasilnya $\mathrm{T}$ hitung $>$ T tabel dan $\mathrm{P}$ value $<0.05$, yaitu $2.776>1.98$ dan $0.006<0.05$ ).

2) Pengaruh kualitas pelayanan terhadap kepuasan pengguna bersifat positif dan juga signifikan, hasilnya ditandai dengan $\mathrm{T}$ hitung $>\mathrm{T}$ tabel dan $\mathrm{P}$ value $<0.05$, yaitu $69.969>1.98$ dan $0.000<0.05$.

3) Pengaruh tidak langsung literasi digital terhadap kepuasan pengguna melalui perantara kualitas pelayanan bersifat positif dan signifikan, yaitu 2.803 sebagai $\mathrm{T}$ hitung $>\mathrm{T}$ tabel $=1.98$ dan $\mathrm{P}$ value $=$ $0.005<0.05$.

Lainnya tetap bersifat positif namun tidak signifikan, sehingga penelitian ini tetap bias diterima.

Setelah melakukan penelitian ini juga diberikan saran sebagai berikut:

1) Pihak manajemen FIP UMJ diharapkan mampu meningkatkan variable literasi digital terutama berkaitan dengan keberfungsian dan manfaat literasi digital itu sendiri agar mahasiswa sebagai user merespon positif perkembangan teknologi dan informasi tersebut. Diberikan juga berbagai pelatihan mengenai literasi digital sehingga kemampuan mahasiswa akan perkembangan teknologi digital meningkat dan nantinya akan lebih berdampak tinggi pada kualitas pelayanan maupun kepuasan menggunakan sistem digitalisasi yang ada di FIP-UMJ.

2) Pihak manajemen FIP UMJ diharapkan mengevaluasi program aplikasi Sikad agar lebih disesuaikan lagi dengan kebutuhan mahasiswa sehingga akan lebih efektif. Ditambahkan pula dengan berbagai pelatihan mengenai Aplikasi Sikad itu sendiri sehingga mahasiwa dapat terus dan lebih memahami dalam penggunaan Aplikasi Sikad demi meningkatkan kepuasan mahasiswa itu sendiri sebagai pengguna utama.

\section{REFERENSI}

Adityar. 2017. Pengaruh Literasi Digital Terhadap Perilaku Internet Berisiko di Kalangan Siswa SMA dan MA di Kota Makassar. Tesis. Program Pascasarjana Fakultas Ilmu Sosial Dan Ilmu Politik Universitas Hasanuddin Makassar.

Agus Dwiyanto, 2012. Mewujudkan Good Governance Melalui Pelayanan Publik, Yogyakarta: Gadjah Mada Press.

Arikunto, Suharsimi. 2011. Prosedur Penelitian suatu Pendekatan Praktik. Jakarta: Rineka Cipta.

Azhar Susanto. 2013. Sistem Informasi Akuntansi. Bandung: Lingga Jaya.

Cornell University. 2009. Laptop ergonomics - 5 Tips for Using a Laptop Computer.

Davies, Sarah. 2015. Spotlight on Digital Capability.

www.digitalcapability.com.

Ernia. E. Elena, 2008. Strategy Frameworkfor Promoting ICT Leteracy in The Asia-Pacific Region. Bangkok: UNESCO Bangkok, Asia and Pacific Regional Bureau for Education.

eLC Research Paper Series. ISSUE 5• Communication \& Learning in the Digital Age | ISSN 2013-7966. eLC Research Paper Series, 5, 14-25.

Fandy Tjiptono dan Gregorius Chandra. 2015. Service, Quality Satisfaction, Yogyakarta: Andi Offset.

Fandy Tjiptono. 2014. Manajemen Jasa. Yogyakarta: Andi Offset.

Fandy Tjiptono, 2009. Prinsip-Prinsip Total Quality Service, Yogyakarta: Andi Offset.

Freddy Rangkuti, 2004. The Power of Brand, Jakarta: PT. Gramedia Pustaka Utama.

Ghozali, Imam. 2011. Structural Equation Modeling Metode Alternatif Dengan 
Partial Least Square (PLS), Semarang: Badan Penerbit Universitas Diponegoro.

Harbani Pasolong. 2011. Teori Administrasi Publik, Bandung: CV. Alfabeta.

Jogiyanto. 2008. Metodologi Penelitian Sistem Informasi. Yogyakarta: CV Andi Offset.

Katz I. R. \& Macklin, A.S. 2008. Information and Communication Technology (ICT) Literacy: Integration and Assessment in Higher Education. Systemics, Cybernetics, and Informatic. Journal.

Kementerian Pendidikan dan Kebudayaan. 2017. Materi Pendukung Literasi Digital. Jakarta 2017.

Murray, D. E. 2005. Technologies for L2 literacy. ARAL, 25, 188b-2001.

Nani Pratiwi. Peran Literasi Digital Terhadap Minat Bersastra Pengguna Media Sosial. Jurnal. Prodi Pendidikan Bahasa dan Sastra Indonesia, Pascasarjana Universitas Negeri Yogyakarta.

Peter C. Verhoef, Jenny van Doorn and Matilda Dorotic. 2005. Customer Value Management: An Overview and Research Agenda. Marketing JRM 2/2007.

Philip Kotler dan Kevin Lane Keller, 2009. Manajemen Pemasaran, Jakarta: Erlangga.

Podhisita, Chai., et al, 2004. Theoritical Terminological, and Philosophical Issues in Qualitative Research, Qualitative Research Methods. Journal.

Rambat Lupiyoadi, 2006. Manajemen Pemasaran Jasa, Jakarta: PT. Salemba Empat.

Ratminto dan Atik Septi Winarsih, 2012. Manajemen Pelayanan, Yogyakarta: Pustaka Pelajar.
Said s. Al-gahtani and Malcolm King. 1999. Attitudes, satisfaction and usage: factors contributing to each in the acceptance of information technology. Journal. Behaviour \& Information Technology, Vol. 18, N0. 4.

Sugiyono. 2015. Metode Penelitian Kuantitatif dan Kualitatif. Bandung: CV. Alfabeta.

Sujadi Kusdiyantoro. 2014. Pengaruh Kualitas Layanan Terhadap Kepuasan Mahasiswa Program Pascasarjana Magister Manajemen STIE Abi Surabaya. Jurnal Bisnis, Manajemen \& Perbankan 1 (2) September 2014.

Surjadi. 2012. Pengembangan Kinerja Pelayanan Publik, Bandung: Refika Aditama.

Tony Wijaya. 2011. Manajemen Kualitas Jasa, Jakarta:PT. Indeks.

VA Zeithaml and Mary Jo Bitner. 2016. Service Marketing. Terjemahan Singapore: Mc Graw-Hill Companies Inc.

Wheeler. S. 2012. Digital Literacies for Engagement in Emerging Online Cultures. Plymouth University United Kingdom.

Widhiarso. W. 2004. Teori dan Praktek Pemodelan SEM. Makalah Pelatihan SEM. Fakultas Psikologi. Yogyakarta: Universitas Gadjah Mada.

Yakub. 2012. Pengantar Sistem Informasi. Yogyakarta: Graha Ilmu.

\section{SUMBER LAIN}

https://pustekkom.kemdikbud.go.id/literas i-digital-sebagai-tulang-punggungpendidikan/ (Diakses pada tanggal: 13 Januari 2019, 09:51 WIB). 
https://online-journals.org > i-jet > article > download (Diakses pada tanggal: 13 Januari 2019, 10:01 WIB).

http://eprints.umm.ac.id/51432/3/BAB\%2 OII.pdf (Diakses pada tanggal: 13 Januari 22:01 WIB).

https://gurudigital.id/jenis-pengertianliterasi-adalah/ (Diakses pada tanggal: 13 Januari 2019, 22:13 WIB).

http://digilib.unila.ac.id/5480/16/BAB\%2 OII.pdf (Diakses pada tanggal: 13 Januri 2019, 22:30 WIB) 